\title{
Effects of Heat, Salt and Hydrocolloid Treatments on Flying Fish Cypselurus agoo Roe Analogs Prepared Using Calcium Alginate Hydrogels
}

\author{
Eun-Hee Jo, Bom-Bi Ha and Seon-Bong Kim* \\ Department of Food Science and Technology/Institute of Food Science, Pukyong National University, Busan 608-737, Korea
}

\begin{abstract}
The present study was conducted to elucidate effects of heat, salt and hydrocolloid treatments on flying fish Cypselurus agoo roe analogs prepared using calcium alginate gel. The changes in size, sphericity and rupture strength of the analogs as affected by treatments of heat, sodium chloride and hydrocolloids were investigated. The size $(\mathrm{mm})$, sphericity $(\%)$, and rupture strength $(\mathrm{kPa})$ of the analogs were $2.2 \pm 0.1,98.2 \pm 0.2$, and $74.7 \pm 1.7$, respectively. When the analogs were heated at $95^{\circ} \mathrm{C}$ in water, the size was slightly decreased. The rupture strength by curing with $2 \%$ sodium chloride was slightly increased. Sphericity didn't show significant differences by sodium chloride and heat treatment. The rupture strength of the analogs was slightly decreased by heat treatment, whereas remarkably decreased by curing with sodium chloride. In order to prevent a remarkable decrease in rupture strength of the analogs by curing with sodium chloride, the analogs were treated with hydrocolloids such as xanthan gum, gum guar, glucomannan, pectin and gelatin. The hydrocolloids treated analogs showed an increment in size and no significant changes in sphericity. On the other hand, the rupture strength of the hydrocolloids treated analogs exhibited remarkable increase than that of untreated ones.
\end{abstract}

Key words: Alginate, Calcium-alginate gel, Flying fish roe, Analog food, Fish roe analog

\section{Introduction}

Alginate is mainly extracted from brown algae and one of the most widely used biopolymer for hydrogels. It is consisted of linear binary copolymers of $1 \rightarrow 4$ linked $\beta$-D-mannuronic acid (M) and $\alpha$-L-guluronic acid (G) residues (Voo et al., 2011). Alginate is an excellent biopolymer possessing properties such as good biocompatibility, good biodegradability, low immunogenicity, non-toxicity and environmental friendly (Rowley et al., 1999; Becker et al., 2001; Martins et al., 2007; Yang et al., 2007).

Alginate forms a thermally stable and biocompatible hydrogels in the presence of di- or tri-cations (Chan et al., 2011). The gel formation occurs due to an ionic interaction between
$\mathrm{G}$ residues from two or more alginate chains and multivalent cations (Augst et al., 2006). The properties of alginate gels are strongly dependent on the ratio of uronic monomers, sequence, cation concentration in the reaction solution, and stabilization time (Smidsrød, 1974; Draget et al., 1994; Velings and Mestdagh, 1995; Ouwerx et al., 1998). Such properties increase water holding capacity in organisms naturally, maintains cells from cultured parent. Alginate also possesses the characteristics of both liquid and gel as it is composed of unique biopolymers compared to other polysaccharides (Draget et al., 1997).

Hydrogel beads are applied in many industrial fields such as in the field of biomedical, bioprocess, pharmaceutical, and
(C) 2014 The Korean Society of Fisheries and Aquatic Science This is an Open Access article distributed under the terms of the Creative Commons Attribution Non-Commercial Licens (http://creativecommons. org/licenses/by-nc/3.0/) which permits unrestricted non-commercial use, distribution, and reproduction in any medium, provided the original work is properly cited.
Received 05 March 2014; Revised 25 March 2014 Accepted 04 April 2014

*Corresponding Author

E-mail: owlkim@pknu.ac.kr 
food industry (Chan et al., 2011). Especially, the application in the biotechnology as well as bio-medical areas is suitable for in vitro culture by regeneration function as well as for the applications of biological tissue engineering (Duff, 1985; Clayton et al., 1993; Colton, 1995; Paige et al., 1996). In addition, it is applied as an immobilization matrix for the encapsulation of biomaterials such as pancreatic islets, and probiotic bacteria and controlled delivery applications (Draget et al., 1997; Brekken et al., 2004). Alginate gel is also capable to be utilized in the encapsulation of highly viscous high-fat food (Blandino et al., 1999).

In the food industry, encapsulation using alginates is most often carried out by producing alginate gel via the extrusiondripping method. An alginate solution is extruded through a capillary and allowed to break away from the nozzle in droplet form under the influence of gravitational force or external force (Lee et al., 2013). Due to electrostatic interactions with calcium ions, alginate gelation is a phenomenon which creates three-dimensional "egg-box" structure owing to the cross-linking of sodium ions in guluronic acid when calcium ions are added into alginate solution (Clark and Ross-Murphy, 1987; Vandenberg and Bell, 2001; Rousseau et al., 2004). The production of fish roe analogs using alginate gel was often influenced some trial-and-error works on the liquid formulation and experimental set-up (Ji et al., 2007; Woo et al., 2007). So, processing of the analogs is required to improve their physical properties such as size, sphericity, rupture strength etc. according to processing conditions.

The present study was conducted to elucidate effects of treatments of heat, salt and hydrocolloid on flying fish roe analogs prepared using calcium alginate gel. The changes in size, sphericity and rupture strength of the analogs as affected by treatments of heat, sodium chloride and hydrocolloids were investigated.

\section{Materials and Methods}

\section{Materials}

Sodium alginate (Junsei Chemical Co., Ltd., Tokyo, Japan) and anhydrous calcium chloride (Junsei Chemical Co., Ltd.) were used for alginate gel. Gum guar, xanthan gum, and glucomannan were provided by MSC Co. (Yangsan, Korea). Gelatin and pectin were purchased from Sigma-Aldrich (St. Louis, MO, USA). All chemicals and reagents used in this study were analytical grade.

\section{Preparation of flying fish roe analogs}

Sodium alginate $(2.6 \%, \mathrm{w} / \mathrm{v})$ was dropped into $1.5 \%(\mathrm{w} / \mathrm{v})$ calcium chloride at a flow rate of $0.06 \mathrm{~mL} / \mathrm{s}$ using SMP-23 Cassette tube peristaltic pump (Eyela, Tokyo, Japan) through the $26 \mathrm{G}(1 / 2 \mathrm{inch})$ nozzle that was connected to a silicon tube. The distance between the nozzle and the surface of the calcium chloride solution was $8 \mathrm{~cm}$. The stirring speed of the reactor in calcium chloride solution was set at $300 \mathrm{rpm}$. The sodium alginate was dropped every $2 \mathrm{~min}$ and stabilized for $31 \mathrm{~min}$ in the solution. The analogs were separated from the solution using a strainer and then washed by distilled water and stored at an ambient temperature.

\section{Salt and heat treatment of the analogs}

Salt treatment was performed by curing the analogs in $2.0 \%$ $(\mathrm{w} / \mathrm{v})$ sodium chloride solution and then physical properties including size, sphericity, and rupture strength of the analogs were determined by Image-Pro Plus (Media Cybernetics, Inc., Bethesda, MD, USA), Bx-50 optical microscope (Olympus, Tokyo, Japan), and CR-100D rheometer (Sun Scientific Co., Ltd., Tokyo, Japan). Heat treatment was carried out by boiling the analogs at $95^{\circ} \mathrm{C}$ and then the physical properties were determined.

\section{Hydrocolloid treatment of the analogs}

Hydrocolloids such as gum guar, xanthan gum, pectin, glucomannan and gelatin were used to treat the analogs. The analogs were immersed in $1 \%(\mathrm{w} / \mathrm{v})$ hydrocolloids maintained at $90^{\circ} \mathrm{C}$ for about $1 \mathrm{~min}$. The hydrocolloids treated analogs were heated at $90^{\circ} \mathrm{C}$ in $2.0 \%(\mathrm{w} / \mathrm{v})$ sodium chloride solution. The physical properties including size, sphericity, and rupture strength were measured by Image-Pro Plus (Media Cybernetics, Inc.), Bx-50 optical microscope (Olympus), CR-100D rheometer (Sun Scientific Co., Ltd.).

\section{Measurement of size}

The size of the analogs was measured by an Image-Pro Plus image analyzer (Media Cybernetics, Inc., Bethesda, MD, USA) coupled to a Bx-50 optical microscope (Olympus, Tokyo, Japan). The image analysis of the analogs was produced at $\times 40$ magnification. For the size of the analogs, the analogs ( 5 per each) were randomly selected and then the average of their maximum diameter and minimum diameter was measured.

\section{Measurement of sphericity}

Sphericity was expressed as the percent ratio of minimum diameter to maximum diameter that was obtained from the diameter measurement of the analogs,

Sphericity $(\%)=\frac{\text { minimum diameter of the analogs }}{\text { maximum diameter of the analogs }} \times 100$ 


\section{Measurement of rupture strength}

Rupture strength was measured using a CR-100D rheometer (Sun Scientific Co., Ltd., Tokyo, Japan) with the following conditions: round-disk stainless steel plunger and $5 \mathrm{~mm}$ diameter. Five samples were used per experiment.

\section{Statistical treatment}

All the results were subjected to analysis of variance, ANOVA $(P<0.05)$ and their means were performed using Duncan's multiple range tests $(\alpha=0.05)$ in the REG procedure of SAS system version 9.01 (SAS Institute Inc., Cary, $\mathrm{NC}, \mathrm{USA}$ ).

\section{Results and Discussion}

\section{Changes in physical properties of the analogs by heat and salt treatment}

The changes in size of the analogs by heat and salt treatment as affected by different treatment time were shown in Fig. 1. Generally, heat and salt treatment is used to enhance storage stability and taste of products. The size of the analogs slightly decreased by heat treatment at $95^{\circ} \mathrm{C}$ for $30 \mathrm{~min}$ compared to intact analogs without heat treatment. Whereas there was no more decrease in size observed when the heat treatment was continued more than $1 \mathrm{~h}$. Such decrease in size of the analogs is considered to be due to dehydration resulting from denaturation of hydrocolloid during the heat treatment. On the other hand, the analogs treated with $2 \% \mathrm{NaCl}$ for $30 \mathrm{~min}$ was slightly increased in size. This is caused by the characteristic of alginate gel which absorbs sodium as well as moisture existing in the sodium solution at the same time (Bang et al., 2002). Moreover, when the analogs were treated with $2 \% \mathrm{NaCl}$ solution more than $30 \mathrm{~min}$, the significant difference was not exhibited in the size of the analogs.

The changes in sphericity of the analogs by heat and salt treatment as affected by different treatment time were shown in Fig. 2. The sphericity (\%) of the intact analogs produced was $98.2 \pm 0.2$, indicating that it was very close to a sphere. The sphericity of the analogs was slightly decreased by heat treatment. In addition, the sphericity of the analogs based on the time period of heat treatment was high ( $92 \%$ to $98 \%$ ). On the other hand, the analogs treated with $2 \% \mathrm{NaCl}$ showed no the significant differences in the sphericity of the analogs. Even though there was difference in sphericity depending on the time period of heat and salt treatment, the difference was not remarkable.

The changes in rupture strength of the analogs by heat and salt treatment as affected by different treatment time were shown in Fig. 3. The rupture strength of the intact analogs prepared was $74.7 \pm 1.7 \mathrm{kPa}$. When the analogs were heated at

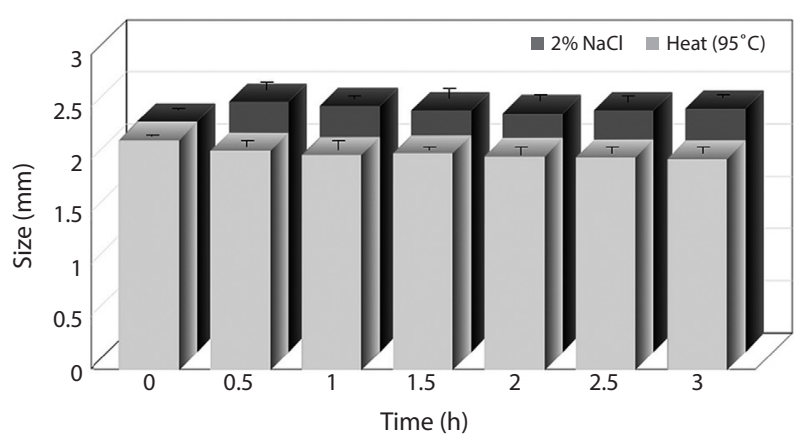

Fig. 1. Changes in size of flying fish roe analogs by treatments of heat and salt as affected by different treatment time. Error bars represent standard deviation (SD, $n=5)$.

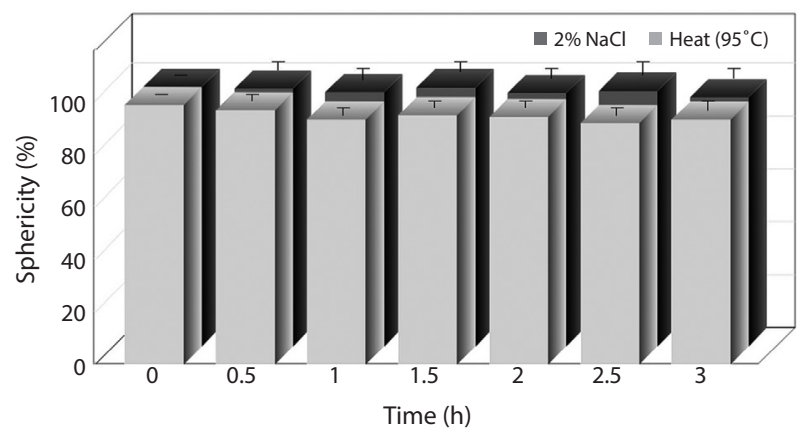

Fig. 2. Changes in sphericity of flying fish roe analogs by treatments of heat and salt as affected by different treatment time. Error bars represent standard deviation (SD, $n=5)$.

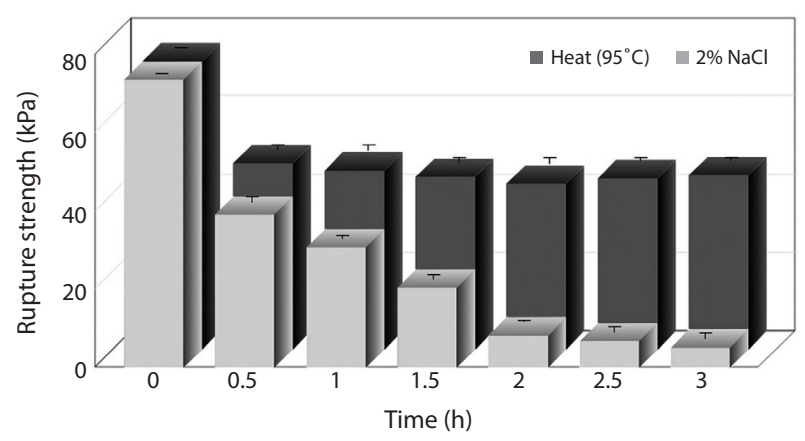

Fig. 3. Changes in rupture strength of flying fish roe analogs by treatments of heat and salt as affected by different treatment time. Error bars represent standard deviation $(S D, n=5)$.

$95^{\circ} \mathrm{C}$, the rupture strength was reduced. The rupture strength of the analogs was decreased until $47.3 \mathrm{kPa}$ by heat treatment for $30 \mathrm{~min}$ but was not decreased when the heat treatment was continued more than $1 \mathrm{~h}$. On the other hand, the rupture strength of the analogs treated by $2 \% \mathrm{NaCl}$ noticeably decreased with the time elapsed. Generally, alginate forms a thermally stable and biocompatible hydrogels in the presence of calcium ion (Chan et al., 2011). The gel formation occurs due to an ionic interaction between $\mathrm{G}$ residues from 


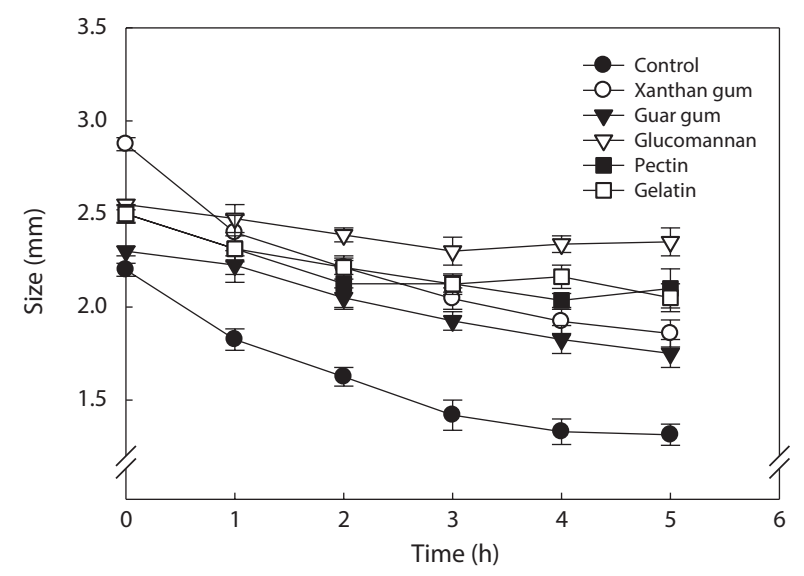

Fig. 4. Changes in size (diameter) of flying fish roe analogs by treatment of hydrocolloids as affected by different treatment time. The treated analogs were heated at $90^{\circ} \mathrm{C}$ in $2.0 \%(\mathrm{w} / \mathrm{v})$ sodium chloride solution. Error bars represent standard deviation (SD, $n=5)$.

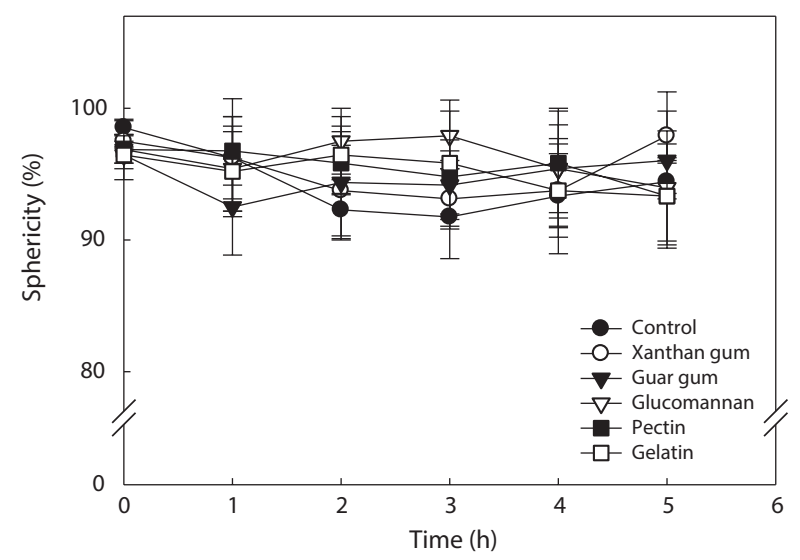

Fig. 5. Changes in sphericity of flying fish roe analogs by treatment of hydrocolloids as affected by different treatment time. The treated analogs were heated at $90^{\circ} \mathrm{C}$ in $2.0 \%(\mathrm{w} / \mathrm{v})$ sodium chloride solution. Error bars represent standard deviation (SD, $n=5)$.

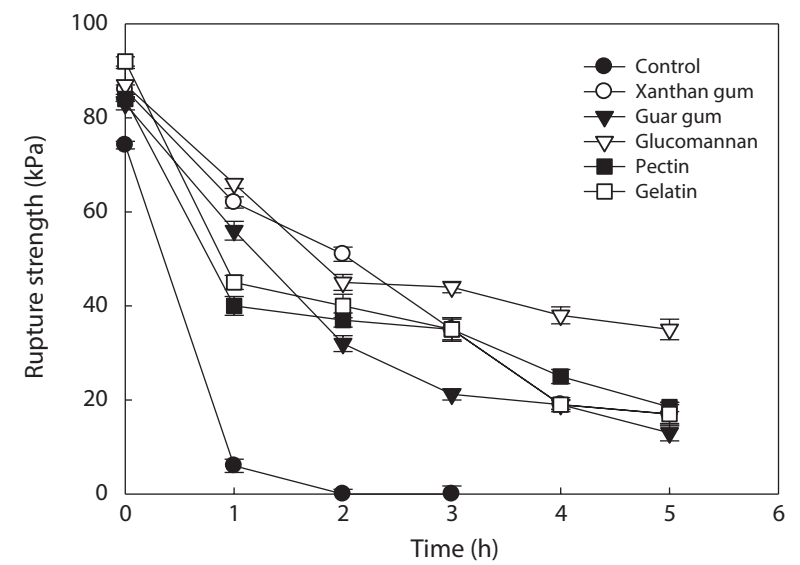

Fig. 6. Changes in rupture strength of flying fish roe analogs by treatment of hydrocolloids as affected by different treatment time. The treated analogs were heated at $90^{\circ} \mathrm{C}$ in $2.0 \%(\mathrm{w} / \mathrm{v})$ sodium chloride solution. Error bars represent standard deviation (SD, $n=5)$. two or more alginate chains and multivalent cations (Augst et al., 2006). Due to electrostatic interactions with calcium ions, alginate gelation is a phenomenon which creates three-dimensional "egg-box" structure owing to the cross-linking of sodium ions in guluronic acid when calcium ions are added into alginate solution (Clark and Ross- Murphy, 1987; Vandenberg and Bell, 2001; Rousseau et al., 2004). By the treatment of $\mathrm{NaCl}$, the chloride ion induces the liberation of calcium ion bound to $\mathrm{G}$ residues of calcium-alginate gel. As a result, it is considered that the rupture strength of the analogs by treatment of salt remarkably decreased with the time elapsed. In order to keep rupture strength of the analogs, the prevention of liberation of calcium ion from the analogs is needed.

\section{Changes in physical properties of the analogs treated with hydrocolloids by salt}

Generally, hydrocolloids such as xanthan gum, gum guar, glucomannan, pectin, and gelatin are much used as thickening and coating agents in food industry. In order to prevent the decrease in rupture strength of the analogs by salt treatment, the analogs were treated with hydrocolloids. Changes in size, sphericity and rupture strength of the analogs by treatment with hydrocolloids were investigated. The changes in size of the hydrocolloid-treated analogs by salt as affected by different treatment time were shown in Fig. 4. Intact analogs were remarkably decreased in size than the hydrocolloid-treated analogs by salt. The hydrocolloid-treated analogs were slightly increased in size and showed no the significant differences in size with the time elapsed. The size of the hydrocolloid-treated analogs was insignificantly affected by kinds of hydrocolloids.

The changes in sphericity of the hydrocolloid-treated analogs by salt as affected by different treatment time were shown in Fig. 5. Noticeable reduction in sphericity of the hydrocolloid-treated analogs was not observed. The sphericity was greater than $90 \%$ in most of the cases and significant differences were not exhibited between the kinds of hydrocolloids.

The rupture strength of the hydrocolloid-treated analogs by salt as affected by different treatment time was shown in Fig. 6. Extremely weak rupture strength was observed when salt was treated in the intact analogs without hydrocolloids treatment. After $1.5 \mathrm{~h}$, it was incapable to measure rupture strength of the intact analogs because the gel was too weak to hold the shape. The rupture strength of hydrocolloid-treated analogs by salt treatment was decreased with time elapsed. The extent of the decrease was lower than that of the intact analogs. The decrease in rupture strength of analogs by salt was inhibited by treatment of hydrocolloids. Among hydrocolloids, glucomannan showed better rupture strength. It is considered that when the analogs were cured with salt, the treatment of hydrocolloids provides better rupture strength than that of the intact analogs. 


\section{Acknowledgments}

This research was supported by a grant from Marine Bioprocess Research Center of the Marine Biotechnology Program funded by the Ministry of Land, Transport and Maritime, Republic of Korea.

\section{References}

Augst AD, Kong HJ and Mooney DJ. 2006. Alginate hydrogels as biomaterials. Macromol Biosci 6, 623-633.

Bang BH and Seo JS. 2002. Characteristics of salt adsorption by calcium alginate beads. J Food Sci Nutri 15, 89-96.

Becker TA, Kipke DR and Brandon T. 2001. Calcium alginate gel: A biocompatible and mechanically stable polymer for endovascular embolization. J Biomed Mater Res 54, 76-86.

Blandino A, Macias M and Cantero D. 1999. Formation of calcium alginate gel capsules: Influence of sodium alginate and $\mathrm{CaCl}_{2}$ concentration on gelation kinetics. J Biosci and Bioeng 88, 686-689.

Brekken C, Thuen M, Singstad TE, Haraldseth O, Sandvig A and Berry M. 2004. A novel probe for localized manganese delivery. In: 3rd Annual meeting of the Society for Molecular Imaging, St. Louis.

Chan ES, Wong SL, Lee PP, Lee JS and Ti TB. 2011. Effects of starch filler on the physical properties of lyophilized calcium-alginate beads and the viability of encapsulated cells. Carbohydr Polym 83, 225-232.

Clark AH and RossMurphy SB. 1987. Structural and mechanical properties of biopolymer gels. Adv Polym Sci 83, 57-192.

Clayton HA, James RF and Long NJ. 1993. Islet microencapsulation: a review. Acta Diabetol 30, 181-189.

Colton CK. 1995. Implantable biohybrid artificial organs. Cell Transplant 4, 415-436.

Draget KI, Skjåk-Bræk G and Smidsrød O. 1994. Alginic acid gels: the effect of alginate chemical composition and molecular weight. Carbohydr Polym 25, 31-38.

Draget KI, Skjåk-Bræk G and Smidsrød O. 1997. Alginate based new materials. Int J Biol Macromol 21, 47-55.

Duff RG. 1985. Microencapsulation technology: A novel method for monoclonal antibody production. Trends Biotechnol 3, 167-170.
Ji CI, Cho SM, Gu YS and Kim SB. 2007. The processing optimization of caviar analogs encapsulated by calcium-alginate gel membranes. Food Sci Biotechnol 16, 557-564.

Lee BB, Pogaku R and Chan ES. 2013. Size and shape of calcium alginate beads produced through extrusion dripping method: a review. Chem Eng Technol 36, 1627-1642.

Martins S, Sarmento B, Souto EB and Ferreira DC. 2007. Insulin-loaded alginate microspheres for oral delivery-Effect of polysaccharide reinforcement on physicochemical properties and release profile. Carbohydr Polym 69, 725-731.

Ouwerx C, Velings N, Mestdagh MM and Axelos MAV. 1998. Physicochemical properties and rheology of alginate gel beads formed with various divalent cations. Polym Gels Netw 6, 393-408.

Paige KT, Cima LG, Yaremchuk MJ, Schloo BL, Vacanti JP and Vacanti CA. 1996. De novo cartilage generation using calcium alginatechondrocyte constructs. Plast Reconstr Surg 97, 168-180.

Reineccius GA. 1991. Carbohydrates for flavor encapsulation. Food Technol 45, 146-149.

Rowley JA, Madlambayan G and Mooney DJ. 1999. Alginate hydrogels as synthetic extracellular matrix materials. Biomaterials 20, 45-53.

Rousseau I, Le Cerf D, Picton L, Argillier JF and Muller G. 2004. Entrapment and release of sodium polystyrene sulfonate (SPS) from calcium alginate gel beads. Eur Polym J 40, 2709-2715.

Smidsrød O. 1974. Molecular basis for some physical properties of alginates in the gel state. Faraday Discuss Chem Soc 57, 263-274.

Vandenberg DA and Bell RA. 2001. How oxygen affects the CMDs and predicted ages of extreme Population II stars. New Astron Rev 45, 577-582.

Velings NM and Mestdagh MM. 1995. Physico-chemical properties of alginate gel beads. Polym Gels Netw 3, 311-330.

Voo WP, Ravindra P, Tey BT and Chan ES. 2011. Comparison of alginate and pectin based beads for production of poultry probiotic cells. J Biosci Bioeng 111, 294-299.

Woo JW, Roh HJ, Park HD, Ji CI, Lee YB and Kim SB. 2007. Sphericity optimization of calcium alginate gel beads and the effects of processing conditions on their physical properties. Food Sci Biotechnol 16, 715-721.

Yang LQ, Zhang BF, Wen LQ, Liang QY and Zhang LM. 2007. Amphiphilic cholesteryl grafted sodium alginate derivative: Synthesis and self-assembly in aqueous solution. Carbohydr Polym 68, 218-225. 